\title{
Quando o artista decide abrir a porta do seu ateliê e começar a olhar à sua volta...
}

When the Artist Decides to Open the Studio Door and Look Outside

Quand l'artiste décide d'ouvrir la porte de son atelier et commence à regarder autour de lui

\section{Sofia Borges}

\section{OpenEdition}

\section{Journals}

\section{Edição electrónica}

URL: http://journals.openedition.org/rccs/5157

DOI: $10.4000 /$ rccs.5157

ISSN: 2182-7435

\section{Editora}

Centro de Estudos Sociais da Universidade de Coimbra

Edição impressa

Data de publição: 1 Dezembro 2012

Paginação: 185-202

ISSN: 0254-1106

\section{Refêrencia eletrónica}

Sofia Borges, «Quando o artista decide abrir a porta do seu ateliê e começar a olhar à sua volta... », Revista Crítica de Ciências Sociais [Online], 99 | 2012, colocado online no dia 04 setembro 2013, criado a 01 maio 2019. URL : http://journals.openedition.org/rccs/5157 ; DOI : 10.4000/rccs.5157 


\title{
Quando o artista decide abrir a porta do seu ateliê e começar a olhar à sua volta...*
}

\begin{abstract}
"Quando o artista decide abrir a porta do seu ateliê e começar a olhar à sua volta..." situa-se no domínio das práticas artísticas e do processo colaborativo com comunidades locais e de outras áreas não necessariamente relacionadas com o campo artístico, como a antropologia. Tem como objeto de estudo o projeto "A festa acabou" (2006-2009) realizado no bairro da Quinta da Vitória por uma equipa constituída por artistas visuais, curadores, antropólogos e pelos moradores do bairro.
\end{abstract}

Palavras-chave: antropologia urbana; arte; cidades; comunidades locais; Quinta da Vitória (Lisboa).

Quando o artista, angustiado com a sua solidão, decide abrir a porta do ateliê e começar a olhar à sua volta, sente necessariamente o impulso para a representação. Quando mais tarde empreender a sua viagem por este mundo fora, vai querer conhecer os lugares por onde passou, recordar o que viu e vai ter a tentação de convidar quem o acolheu, como quem lhe mostrou novos caminhos.

A arte foi sempre ao encontro de outros lugares. Pela mão dos artistas reteve outras formas de vida e pensamentos. No século XIX a arte vai expor assuntos que não eram habituais na pintura. O Realismo vai reter a vida quotidiana dos trabalhadores e camponeses, denunciando assimetrias sociais através da representação dos mais desfavorecidos.

No século XX assistimos a uma proliferação de estilos e a uma constante reformulação do conceito de arte. Daqui para a frente, cada artista vai ao encontro do seu lugar e da sua própria forma de representação. Algumas vezes impulsionado por uma necessidade própria, outras associando-se às

\footnotetext{
* Os objetos artísticos e documentais produzidos no âmbito do projeto "A festa acabou"(2006-2009) encontram-se na posse de Sofia Borges e Vasco Coelho, sendo que os materiais provenientes da recolha etnográfica no bairro da Quinta da Vitória estão arquivados numa base de dados de acesso restrito. Em discussão está a possibilidade de consulta pública.
} 
profundas mudanças culturais e sociais desencadeadas pelos movimentos cívicos, culturais e políticos que acompanharam o movimento Negritude ${ }^{1}$ e posteriormente a descolonização, a luta pelos direitos das minorias e o movimento feminista, como alguns exemplos que vieram abrir caminho à inclusão de outros intervenientes e à reconfiguração dos modelos de representação social e políticos vigentes.

Com esta reaproximação ao contexto político, os movimentos artísticos vão procurar

responder ao que se apresentava naquele tempo, os anos 60, como necessidade de articular a produção cultural em termos de inconformismo e desmitificação; vincular a experimentação da linguagem às possibilidades de uma arte participante, agenciando nas aç̧ões uma outra ordem de simbólico - o comportamento -, visando a vontade de "instaurar um novo mito"; uma imagem da arte como actividade onde não se distinguem os modos de efectivar programas estéticos e exigências ético-políticas. (Favaretto, 2010: 68)

Esta aproximação à realidade circundante manifesta-se em diferentes formas de expressão. A performance e o happening vêm convocar o público para o centro da ação artística, recorrendo a dispositivos sensoriais que estimulam a participação, com o objetivo de diluírem fronteiras que separaram o objeto artístico e o público.

Tal como a performance, também a Land Art vem introduzir processos de pesquisa e exploração que privilegiam a relação com um determinado lugar.

A Land Art e o site-specific vêm inaugurar um novo campo de experimentação e reflexão sobre o conceito de lugar. Ainda que este lugar fosse entendido como um espaço delimitado pelas suas propriedades físicas e características geográficas, $[\ldots .$.$] a$ Land Art vem introduzir novos processos de pesquisa e produção como a cartografia, o registo, a documentação, o arquivo e a colecção, posteriormente absorvidos pelos artistas no campo das práticas colaborativas. ${ }^{2}$ (Borges, 2010: 13)

Já nos anos 90, como reação ao desenvolvimento do modelo capitalista e do mercado de arte vigente, os artistas vão procurar alternativas, desenhando

\footnotetext{
${ }^{1}$ Negritude é um conceito definido nos anos 40 e 50 por Aimé Césaire e Léoplod Sédar, dirigentes do movimento Negritude, através do qual afirmaram as suas raízes africanas contra a "violência selvagem do colonizador, o relativismo moral do cristianismo e o racismo europeu à semelhança da barbárie". Estas expressões foram utilizadas na comunicação do manifesto do movimento (consultado a 24.04.2011, em http://www.youtube.com/watch?v=Mok1XYQ-p3Y).

2 A expressão "práticas colaborativas" é utilizada para definir práticas artísticas que privilegiam o envolvimento de comunidades locais durante a pesquisa e algumas vezes, diretamente no processo criativo.
} 
novos modelos de produção e divulgação da arte e tentando encontrar outros lugares e outros intervenientes.

Como resposta ao contexto social e político vigente, surge a necessidade de encontrar outros modelos de representação social. Neste contexto, os artistas começam a desenvolver os seus projetos em locais específicos, junto dos intervenientes locais, com base em processos de colaboração, operando como mediadores e questionando os modelos de representação sociais e políticos vigentes.

Segundo Hal Foster, a antropologia, como ciência da alteridade, assume um papel preponderante nesta discussão:

como a psicanálise, a língua franca tanto da prática artística como do discurso crítico. Em segundo lugar, é a disciplina que constitui/institui a cultura como seu objecto [...] em terceiro lugar, a etnografia é considerada como sendo contextual, uma exigência frequentemente automática que os artistas e críticos contemporâneos partilham actualmente com outros praticantes [...] Em quarto lugar pensa-se que a antropologia arbitra o interdisciplinar, um outro valor mecânico na arte e crítica contemporânea... (Foster, 2005: 274)

No contexto teórico surge um interesse crescente pela natureza colaborativa desta prática artística e a discussão alarga-se a outros campos. A diversidade de propostas origina uma diversidade de termos. A par de designações habituais como as de "arte colaborativa" ou "arte participativa", surgem outras, incluindo as apontadas por Grant Kester (2004a) como recorrentes: new genre of public art (Lucy Lippard), relational aesthetic (Nicolas Bourriaud) e conversational art (Homi Bhabha).

Para Kester (2010), a arte colaborativa pode compreender tanto a colaboração direta das comunidades, como a coautoria ou a participação do público.

Para Miwon Kwon estes projetos estão ligados a formas de representação política e agenciamento artístico (ativismo político e social pela arte), pressupõem um envolvimento direto das comunidades e não têm necessariamente de produzir algo em concreto, podendo privilegiar o processo e a intervenção local (apud Kester, 2004b: 11). Claire Bishop (2006) vem definir dois modelos de colaboração:

[um modelo onde] os artistas recorrem à criação de objectos artísticos e à utilização de dispositivos expositivos, como galerias, museus e bienais de arte, e parecem estar tão interessados nas questões políticas como na qualidade estética dos objectos produzidos. E outro modelo, onde os artistas tendem a substituir os meios tradicionais de produção e divulgação da arte, por discussões públicas, acções locais, debates e pela apresentação 
da documentação do processo. Privilegiando o envolvimento com os intervenientes locais e as questões éticas, à produção de objectos artísticos. (Borges, 2010: 10)

Por outro lado, Hal Foster chama a atenção para o risco de os artistas partirem de ideias pré-definidas e fantasias com "roupagens neoprimitivistas" (2005: 288), de comprometerem o processo colaborativo por dificuldades em manter o afastamento ou a proximidade necessários, ou de valorizarem os aspetos estéticos, em detrimento da relação com as comunidades envolvidas no processo.

Independentemente do posicionamento de cada artista, o processo colaborativo conduz-se necessariamente por um conjunto de questões éticas, como a legitimidade de o artista intervir nos locais em questão, o seu grau de envolvimento e a natureza da colaboração, ou a qualidade estética dos objetos produzidos neste contexto.

Para lá das questões estéticas que estes projetos podem propor, o interesse da prática colaborativa é sustentado pela possibilidade de se gerar uma rede discursiva transdisciplinar, compreendendo disciplinas como a arte, a filosofia, a antropologia e o urbanismo, e a possibilidade efetiva de esta reflexão ser alargada ao domínio público com a discussão destes lugares e comunidades.

\section{Caso de estudo}

Apresentados os antecedentes que podem ter impulsionado a aproximação da arte ao lugar e, como consequência, às comunidades locais, algumas das questões subjacentes ao processo colaborativo, a diversidade de propostas e a transdisciplinaridade desta discussão, proponho agora a apresentação do projeto "A festa acabou", ${ }^{3}$ realizado no bairro da Quinta da Vitória, ${ }^{4}$ situado na periferia de Lisboa, onde participei como artista visual e curadora.

O projeto surge do cruzamento entre a prática artística e os estudos curatoriais, que fundamentam esta exposição. Posteriormente, vieram a

\footnotetext{
${ }^{3} \mathrm{Na}$ ficha técnica do projeto "A festa acabou" incluem-se, na pesquisa e conceção Ana Gonçalves, Vasco Coelho e Sofia Borges; na curadoria Vasco Coelho e Sofia Borges; na consultoria de pesquisa Marta Barreira Carvalho; na assistência à montagem Rui Palmeiro; no design gráfico Vitor Azevedo; na colaboração Inácio Francisco Kalenda, Mónica Miranda e Rui Viana Pereira; nos textos Alexandre, Joice, Tina, Laura, Ema, Catarina e Gina (crianças do bairro da Quinta da Vitória), Dr. ${ }^{a}$ Geni Veloso (Presidente da Junta de Freguesia da Portela), Marta Carvalho, Rita d'Ávila e Sofia Borges; no apoio a Faculdade de Belas Artes de Lisboa e a Junta de Freguesia da Portela; na divulgação projeto artístico "Underconstrution" de Mónica de Miranda com a curadoria de Paul Goodwin.

${ }^{4} \mathrm{O}$ bairro da Quinta da Vitória situa-se na fronteira entre os municípios de Lisboa e Loures, junto à Urbanização da Portela, perto do aeroporto de Lisboa. A sua construção iniciou-se nos anos 60 , por pessoas provenientes do interior do país. Nos anos 70, com a descolonização, chegaram outros moradores vindos das ex-colónias, com o mesmo sonho de ter uma casa, um trabalho e constituir uma família. A partir de 1993 teve início o PER (Programa Especial de Realojamento), um programa que previa o realojamento dos moradores em bairros sociais. Este processo prolongou-se durante vários anos. Quando chegámos ao bairro, em 2006, alguns moradores já o tinham deixado e outros continuavam a aguardar realojamento.
} 
colaborar outras áreas disciplinares não diretamente relacionadas com o campo artístico, como a antropologia.

Este projeto nasce da necessidade de contribuir para uma história mais inclusiva do bairro, que funcionasse como contraponto às imagens habitualmente difundidas pela opinião pública, associadas na maioria das vezes à violência, ao crime, à pobreza e exclusão destes lugares.

A construção de um mapa surge como objeto aglutinador desta questão, a medida em que o bairro estava na iminência de ser demolido, sem qualquer cartografia. Como se registou no projeto inicial:

Quando chegámos ao bairro as demolições tinham sido temporariamente suspensas, depois de um realojamento massivo dos moradores que moravam na zona administrada pelo Município de Lisboa (2000) [...] Apesar do nosso objectivo não estar directamente relacionado com as demolições, fomos profundamente influenciados pela ideia do bairro vir a desaparecer sem qualquer registo, memória e associado a uma imagem negativa, como a maioria dos bairros auto-construídos. Tudo indicava que a Quinta da Vitória iria desaparecer sem deixar qualquer rasto. Não havia (2006) qualquer registo nos mapas da cidade de Lisboa (Google, Corte Inglês e Câmara Municipal de Lisboa) [... Interrogados por estes factos, avançámos com a ideia de construir um mapa do bairro com a colaboração dos moradores partindo da expectativa que este mapa pudesse conservar a identidade e a memória dos moradores da Quinta da Vitória. (Borges, 2010: 26)

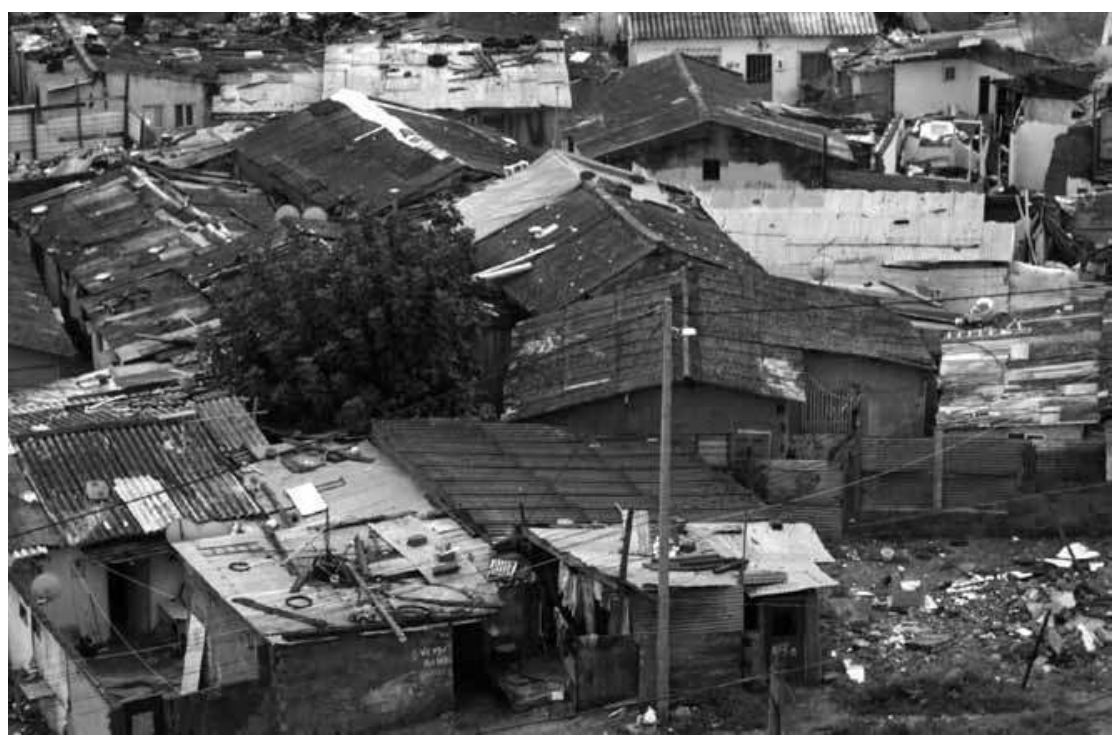

FIGURA 1 - Vista aérea sobre o Bairro da Quinta da Vitória

Fonte: Vasco Coelho e Sofia Borges 
Registam-se aqui alguns dos pressupostos e questões definidas inicialmente, que contribuíram para implementar estratégias e fundamentar este processo: a) a maioria destes bairros está associada a imagens distorcidas, representações abstratas e preconceitos que contribuem para o seu isolamento, tal como a diferença, o medo, a pobreza e o alheamento têm contribuído para a exclusão social e silenciamento destas comunidades; b) como aceder ao bairro, se partíamos de uma ideia abstrata desta realidade?; c) será que o mapa pode ser o elemento que funciona como interface e aglutinador de um processo colaborativo, através do qual os moradores têm a possibilidade de participar na construção de uma imagem do bairro? d) de que forma se poderá salvaguardar os materiais recolhidos?; e) a quem pertencem estes materiais?; f) será que o museu de arte pode acolher estes materiais e contribuir para a discussão destas comunidades?; e finalmente, g) será que o museu de arte é também o lugar de reinscrição histórica? (Borges, 2010: 35).

Este projeto veio a desenvolver-se em três etapas: a primeira fase consistiu na pesquisa de campo no bairro, onde participaram artistas visuais e antropólogos, em colaboração com os moradores; na segunda fase foram produzidas as peças elaboradas pelos artistas; e, por último, teve lugar a exposição final realizada no bairro da Quinta da Vitória, onde participaram os artistas visuais e os moradores do bairro.

Os artistas visuais e antropólogos partilharam a conceptualização deste projeto, tendo desenvolvido ainda durante a pesquisa de campo uma série de ações com o objetivo de recolher os materiais no bairro e envolver os moradores no projeto. Em conjunto promoveram diversas reuniões no bairro e realizaram questionários, recolhendo testemunhos, histórias, acontecimentos e objetos que representavam as imagens que os próprios moradores tinham do bairro; distribuíram máquinas fotográficas e gravadores para que fosse possível o registo de lugares de referência; identificaram árvores e hortas e a reconstruíram a cartografia do bairro, identificando as ruas e becos, as casas e os lugares vazios deixados pelas demolições.

Quando concluída a pesquisa de campo, artistas e antropólogos participaram em conjunto na organização dos materiais, ${ }^{5}$ que vieram a servir de

\footnotetext{
${ }^{5}$ Os arquivos dos materiais recolhidos foram organizados segundo: 1) "Árvores, plantas e hortas" (mapeamento e registo das árvores); 2) "Questionários" (resposta dos moradores elaborados sobre a sua imagem do bairro; 3 ) "Como é que as crianças veem o bairro?" (fotografias e gravações áudio do workshop); 4) "Demolições" (materiais relacionados com as demolições); 5) "Frases" (frases dos moradores); 6) "Média" (notícias sobre o bairro da Quinta da Vitória); 7) "Exposição em construção" (aspetos da arquitetura, da construção e elementos gráficos); 8) "Objetos" (fotografias dos objetos recolhidos), 9) "Documentação" (arquivo do diário de campo e fotografias) e 10) "Som" (registos de ambientes sonoros e entrevistas).
} 
referência e matéria para a criação dos objetos apresentados na exposição realizada no bairro da Quinta da Vitória.

Dada a diversidade dos materiais, definiu-se a organização de arquivos de acordo com; 1) os meios e ferramentas utilizados durante pesquisa de campo, como os questionários, as gravações sonoras ou o workshop com as crianças do bairro; 2) os temas sugeridos pelos moradores, como as demolições e os meios de sobrevivência; 3 ) e outros definidos pelos artistas e antropólogos, resultantes da pesquisa de campo no bairro, nomeadamente assuntos relacionados com a imagem do bairro, como o arquivo de recortes de notícias de jornais sobre o bairro da Quinta da Vitória.

Para lá de os antropólogos terem participado em todas as fases do projeto até aqui referidas, a sua colaboração "... reflectiu-se sobretudo na introdução de técnicas de investigação antropológica como o diário de campo, histórias de vida e entrevistas" ${ }^{6}$ Contribuíram significativamente para a identificação de lugares e interlocutores de referência, estratégias de colaboração com os moradores e para a interpretação dos objetos recolhidos, como se registou no diário de campo:

Expliquei-lhe o que fazia e o motivo pelo qual queria trabalhar com ela. Esforcei-me por dar uma imagem vívida do meu enquadramento, o que provocou gargalhadas incrédulas ("[os objectos] têm um nascimento?", e dobrava-se sobre si própria, a rir). Mas acho que percebeu a ideia e ficou interessada... fazia perguntas e dava exemplos, e acho que esta história de traçar biografias de coisas é para ela uma ideia a descobrir. A certa altura achei importante expor a questão da "consciência da escolha", até porque ela própria me pareceu de repente mais distanciada das plantas. Olhou para mim com ar pensativo e disse "agora estou a pensar em dois objectos: um pau para mexer arroz e um cabaz [cabaça?]”. São objectos tradicionais guineenses e explicou-me pormenorizadamente este último [...] Sobre o outro objecto falámos pouco, até porque apercebi-me que estes objectos eram coisas que tinha na Guiné, portanto difíceis de trabalhar aqui... (Borges, 2010: 46)

\footnotetext{
6 "Diário de campo é um registo diário da observação participante, no qual se relata a experiência do antropólogo em relação com os estudados, o que dizem, o que fazem e o que pensam [...] É uma forma de ordenação das notas e um instrumento de autodisciplina. Este é um instrumento de controlo da investigação, pois nele reflecte-se como se produz o conhecimento, orientando a subjectividade e o papel do investigador no terreno [...] Histórias e relatos de vida são relatos sobre a vida de uma pessoa, ainda que as primeiras incluem documentos que completem a oralidade biográfica. Esse relato informa não só sobre a vida dela, porém também sobre a vida da comunidade e os seus valores, o passado e o presente. Para verificar esta deveremos ter em atenção a coerência interna do relato, a informação proporcionada por outras pessoas, a observação participante e a avaliação externa através de documentos e outros [...] Entrevista oral esta técnica de investigação, é um procedimento operativo para obter uma informação através do diálogo intersubjectivo com uma pessoa..." (Pereiro, 2004-2005).
} 


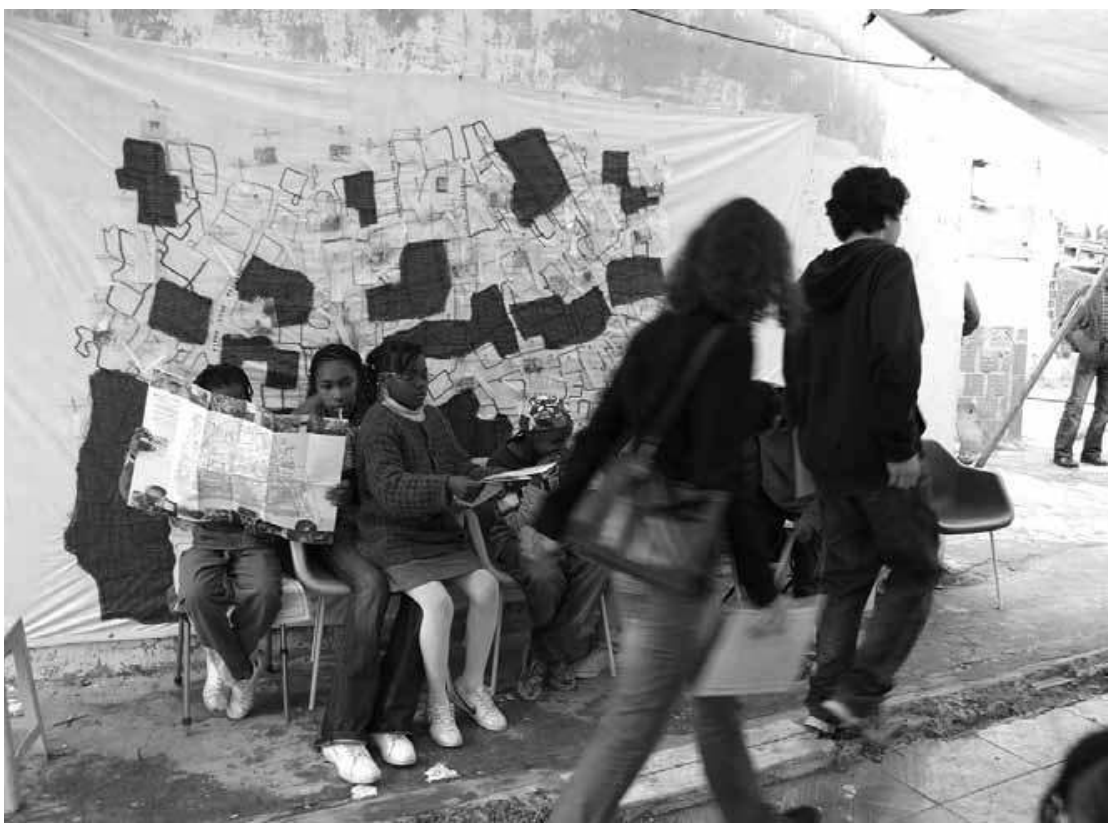

FIGURA 2 - "Mapa" do Bairro da Quinta da Vitória

Fonte: Vasco Coelho e Sofia Borges

Concluído o arquivo dos materiais, estabeleceram-se os núcleos temáticos e expositivos que conduziram os artistas à criação e realização de um conjunto de peças e intervenções públicas no bairro.

O "Mapa" constituiu-se como a peça central e aglutinadora dos materiais recolhidos em campo. Foi construído sobre um tecido de grandes dimensões $(2,10 \mathrm{~m}$ x $3,40 \mathrm{~m})$ para conter os vários elementos reveladores de uma cartografia do bairro, onde se definiu o desenho das casas com fitas "gregas" de várias cores, as casas demolidas, as ruas, as travessas e os becos, a maioria só do conhecimento dos moradores. Nele se fixaram pequenos sacos (herméticos) de várias dimensões com os elementos recolhidos em campo: fotografias dos objetos, frases dos moradores, histórias, imagens do bairro, fotografias das árvores e das hortas e, por fim, recortes de notícias do bairro recolhidos em jornais durante a realização deste projeto.

\footnotetext{
7 Ficha técnica: "Mapa", realização de Ana Gonçalves, Vasco Coelho, Sofia Borges com a colaboração dos moradores; 2,10 m x 3,40 m; pano-cru com aplicações de diversos materiais recolhidos no bairro da Quinta da Vitória e outros como fitas de nastro, redes de plástico utilizadas na construção civil; 2009.
} 
Se o "Mapa" foi o fio condutor da pesquisa de campo, na medida em que estabeleceu a necessidade de recolher materiais e de definir uma cartografia, todas as outras peças surgiram durante a pesquisa de campo e posteriormente, quando se estudaram os materiais recolhidos.

Neste âmbito realizou-se um conjunto variado de peças: um vídeo ("Eu era produtor de mim próprio"); uma série de fotomontagens de grandes formatos a partir do aproveitamento e função das plantas usadas pelos moradores ("Vamos perder aquela abacateira do meio das barracas"); uma intervenção no espaço público ("Tudo o que nós não sabemos dos outros sítios, nós sabemos deste)" e um catálogo do projeto.

"Eu era produtor de mim próprio" ${ }^{8}$ foi realizado a partir dos temas abordados pelos moradores durante as entrevistas no bairro e de fotografias recolhidas no local. Neste vídeo, os moradores falam sobre a história do bairro da Quinta da Vitória: desde a chegada dos primeiros moradores e a construção das casas de madeira à instalação da luz elétrica nos anos 80 , ao impacto das demolições e expectativas sobre o realojamento, aos meios de sobrevivência, como o cultivo de hortas, a criação de animais e o comércio local, aos laços afetivos com vizinhos e aos núcleos familiares alargados; falam ainda sobre o medo e os preconceitos das pessoas que nunca entraram no bairro e a imagem negativa veiculada pelos meios de comunicação.

"Vamos perder aquela abacateira do meio das barracas" é uma série de fotomontagens realizada a partir de fotografias das árvores, plantas e hortas do bairro, como uma evidência das relação com a terra e meios de sobrevivência.

"Tudo o que nós não sabemos dos outros sítios, nós sabemos deste"10 é uma instalação e intervenção no espaço público, constituída por cartazes com frases dos moradores, onde se abordam aspetos da identidade e histórias do bairro relacionados com a vida dos moradores, os meios de sobrevivência, as relações afetivas e comunitárias.

\footnotetext{
${ }^{8}$ Ficha técnica: "Eu era produtor de mim próprio", DV, 13', 1:1, 33, cor; realização de Sofia Borges com a colaboração de Vasco Coelho, Marta Carvalho, Rui Viana Pereira e dos moradores do bairro da Quinta da Vitória; produção de "A festa acabou"; som de Rui Viana Pereira. Portugal, 2009.

9 Ficha técnica: "Vamos perder aquela abacateira no meio das barracas" realização de Vasco Coelho com colaboração Sofia Borges, Marta Carvalho, Rui Viana Pereira e dos moradores do bairro da Quinta da Vitória; produção de "A festa acabou"; dimensões variáveis; impressão de fotocópias a cores em folhas A4; 2009.

${ }^{10}$ Ficha técnica da instalação "Tudo o que nós não sabemos dos outros sítios, nós sabemos deste": montagem no espaço público com série de 14 cartazes; realização de Sofia Borges, Vítor Azevedo, Vasco Coelho, Marta Carvalho, com a participação das crianças do bairro; dimensões variáveis; impressão de fotocópias a cores em folhas A4; 2009.
} 
194 | Sofia Borges
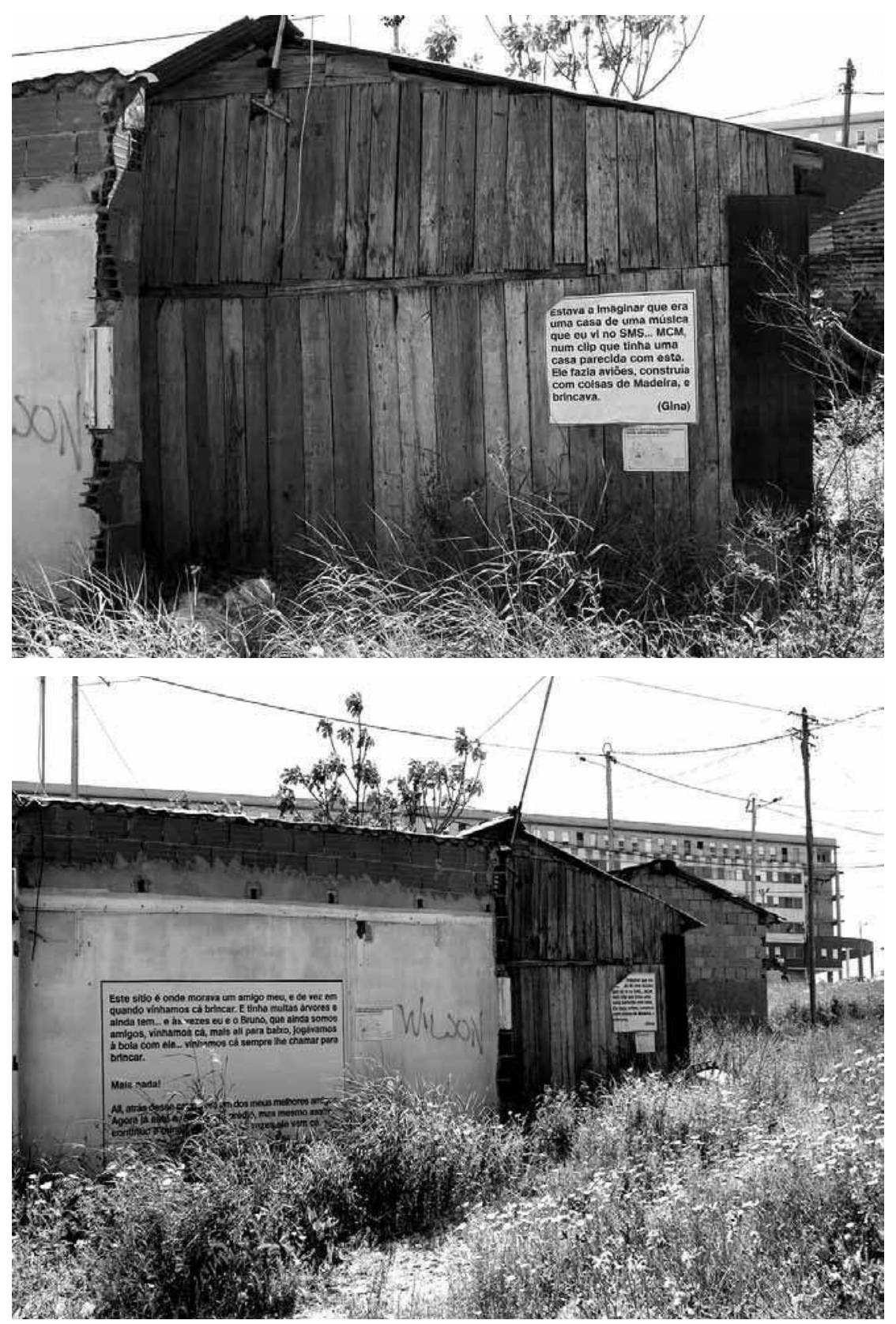

FIGURAS 3 e 4 - "Tudo o que nós não sabemos dos outros sítios, nós sabemos deste"

Fonte: Vasco Coelho e Sofia Borges 


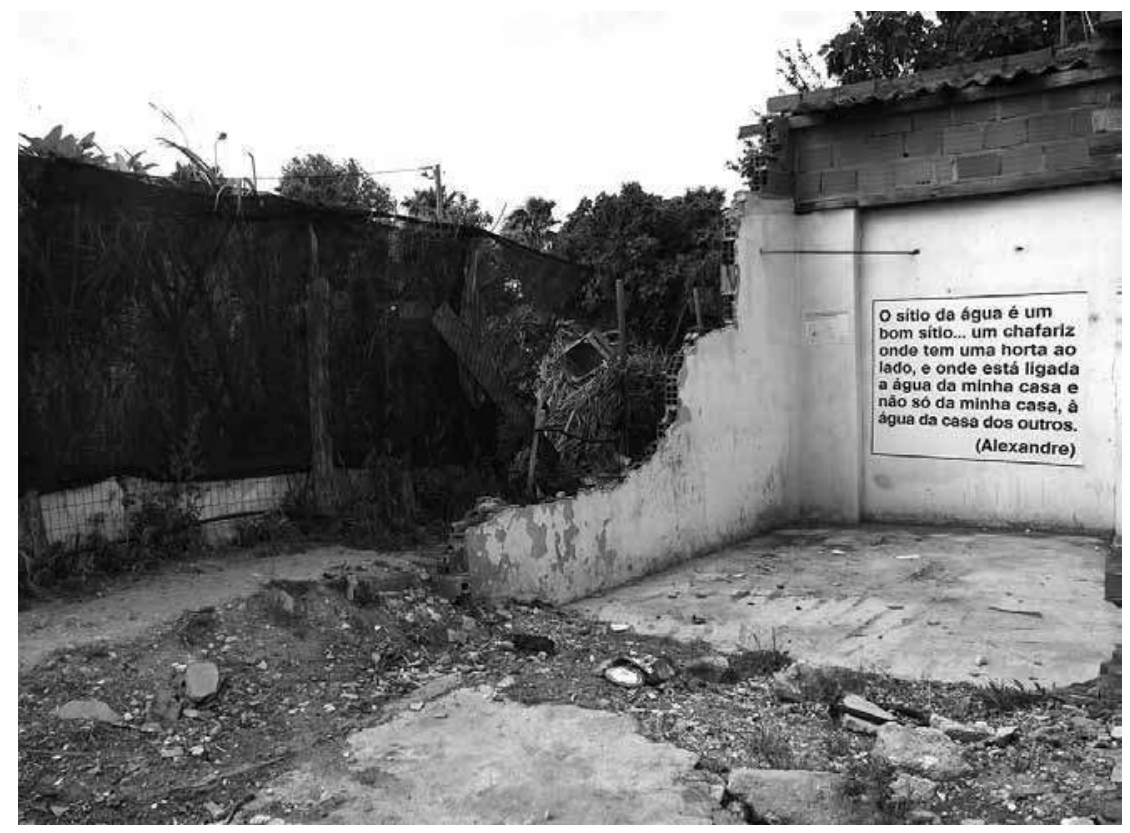

Figura 5 - “Tudo o que nós não sabemos dos outros sítios, nós sabemos deste"

Fonte: Vasco Coelho e Sofia Borges

Através da instalação em locais demolidos, procurou-se não só revelar aspetos que marcam a identidade do bairro, como pôr em destaque o impacto das demolições. Como se regista neste cartaz (n. $\left.{ }^{\circ} 14\right)$ :

E houve um dia que eu viajei e não sabia que a casa ia ser partida. Quando eu vim o meu pai disse que a casa deles ia ser partida. Depois de manhã eu vinha despedir deles e quando eu vim a casa já estava toda partida, cheia de lixo depois fui-me embora a chorar. E depois vi a minha amiga e ela perguntou, o que é que foi e eu disse: A casa da Maria já se partiu. E ela disse: Já! Depois começou a chorar comigo, e fomos as duas brincar sozinhas. Mais nada! (Joice)" (cartaz colado perto do local onde tinha vivido a Maria; Borges, 2010: 31) 


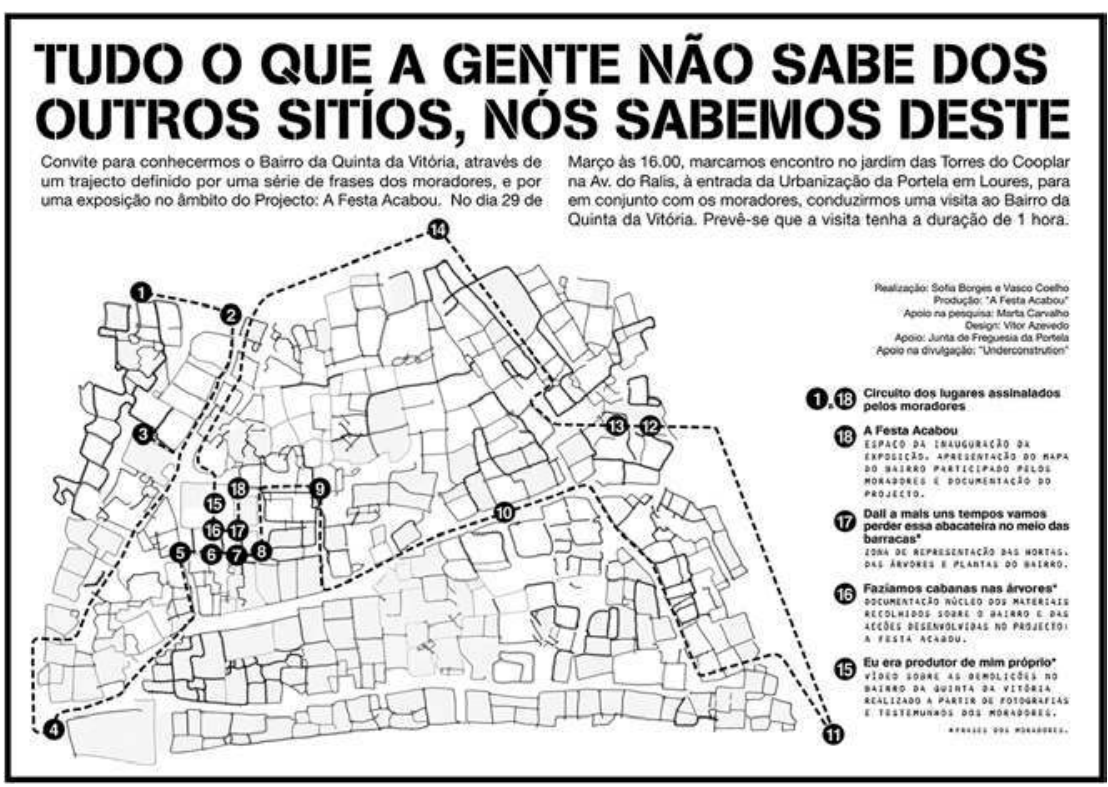

FIGURA 6 - Percurso da visita guiada no bairro

Fonte: Vitor Azevedo

No dia da inauguração da exposição realizou-se também uma visita guiada ao longo de um percurso, onde foram comentados os cartazes (Figura 6). Desta forma procurou-se contextualizar o bairro e introduzir a temática trabalhada nas peças apresentadas na exposição.

Para além dos moradores, participaram nesta visita associações dos bairros vizinhos, movimentos cívicos e políticos do direito à habitação, que tinham organizado diversas manifestações no interior do bairro, artistas visuais e investigadores da área das ciências sociais.

A exposição ${ }^{11}$ intitulada "A festa acabou" foi montada num lugar vazio, deixado por um conjunto de casas demolidas. Projetou-se em torno de uma estrutura central construída no local, semelhante a uma tenda. No interior deste espaço, coberto com lonas azuis, apresentou-se o vídeo, "Eu era produtor de mim próprio" e no exterior, os textos dos vários colaboradores

\footnotetext{
${ }^{11}$ Ficha técnica do projeto expositivo "A festa acabou": curadoria de Vasco Coelho e Sofia Borges; conceção e realização: Vasco Coelho e Sofia Borges com a participação dos moradores; produção de "A festa acabou"; assistência à montagem de Rui Palmeiro; divulgação de Jorge Rocha; apoio da Junta de Freguesia da Portela; Loures - Bairro da Quinta da Vitória; Março de 2009.
} 
do projeto, entre os quais artistas visuais, antropólogos, moradores e a autarquia local que apoiou este projecto. ${ }^{12}$

As fotomontagens das plantas foram coladas numa parede do beco que dava acesso à exposição e o "Mapa" foi montado perto do núcleo central. Toda a área foi coberta com lonas azuis e ao centro foi construída uma estrutura com um bidão metálico e uma porta recolhida nas demolições, que servia de suporte aos catálogos, distribuídos às pessoas que estiveram presentes na exposição (Figura 7).

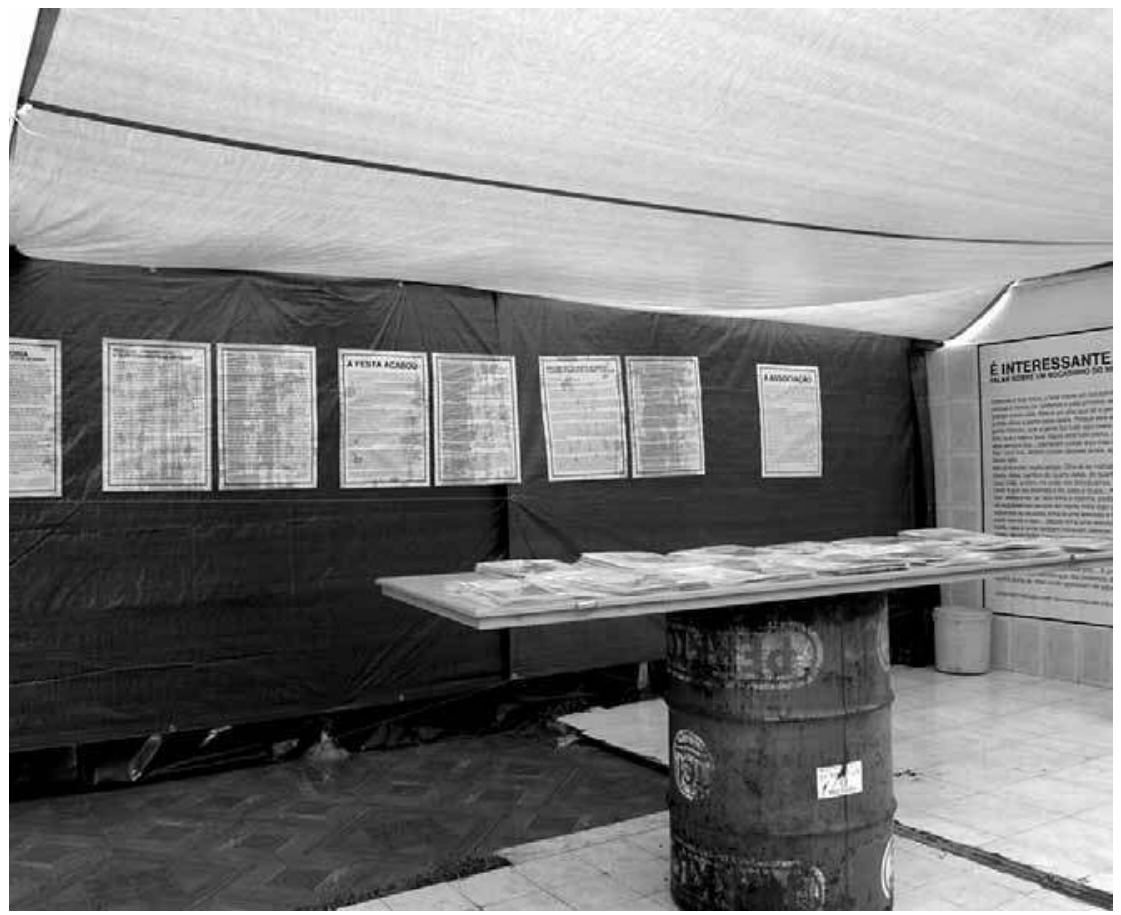

FIGURA 7 - Exposição realizada no bairro da Quinta da Vitória

Fonte: Sebastião Pires

${ }_{12}$ Textos: "Pesquisa, comunicação e questionamento do lugar" de Marta Carvalho; "A festa acabou" de Sofia Borges; "Projecto A festa acabou - Bairro da Quinta da Vitória" da autarquia local; "Quinta da Vitória: um pequeno resumo da história do bairro" de Rita d' Ávila; "Associação" e "É interessante falar um bocadinho sobre o nosso bairro..." de Joice, Laura, Gina, Alexandre e Catarina, moradoras do bairro da Quinta da Vitória. 

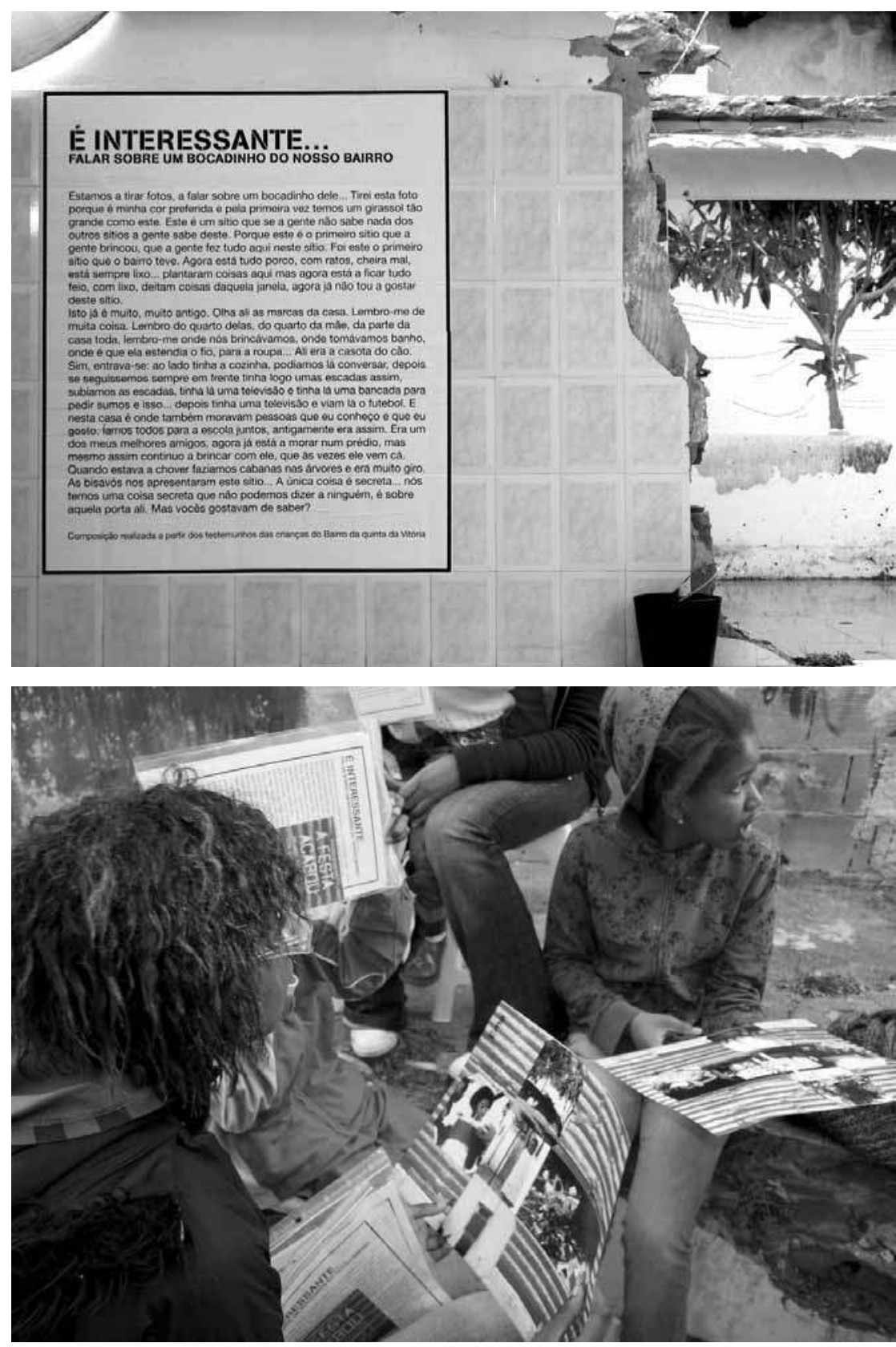

FIGURAS 8 e 9 - Exposição realizada no bairro da Quinta da Vitória

Fonte: Sebastião Pires 


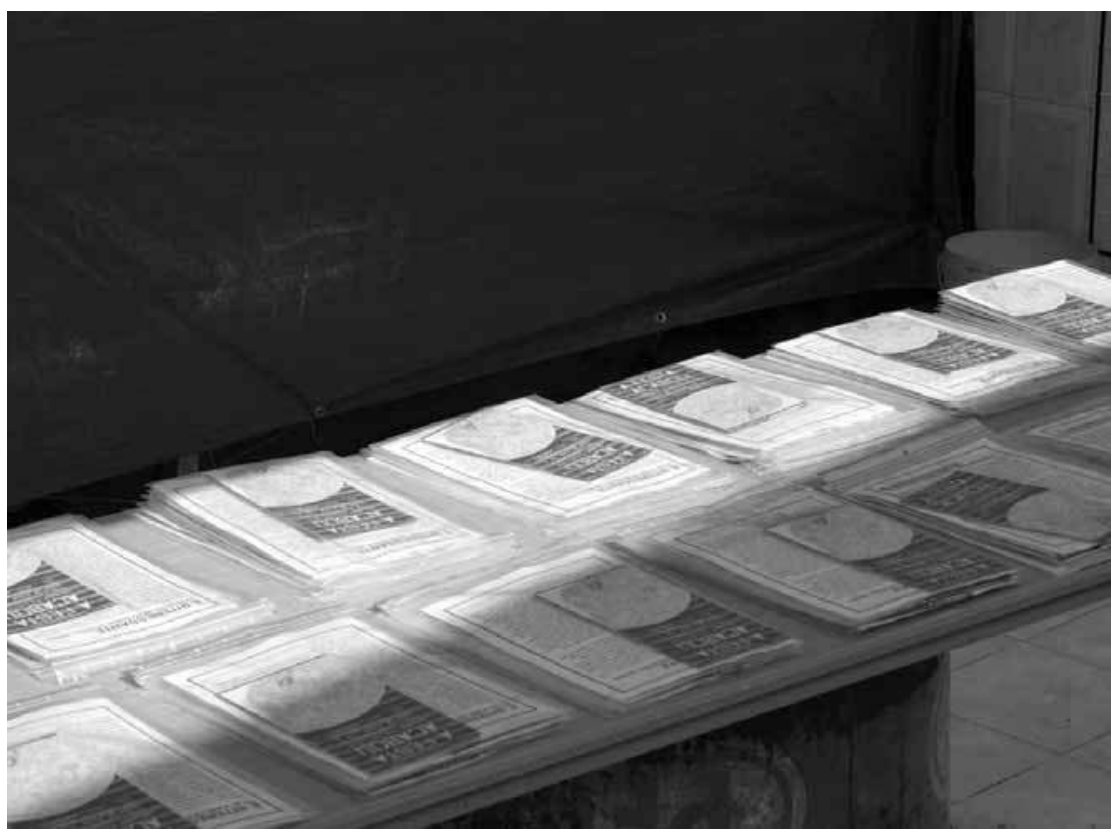

Figura 10 - Catálogos do projeto "A festa acabou"

Fonte: Sebastião Pires

Os catálogos (Figura 10) funcionavam como um depósito de materiais. Para lá dos textos dos colaboradores, já referidos, continham um mapa desdobrável semelhante a um mapa turístico, onde se apresentava a localização da Quinta da Vitória na cidade de Lisboa, e os núcleos da exposição no mapa do bairro, para além das respetivas árvores e hortas, as fotografias dos objetos entregues pelos moradores como uma máquina de costura, ervas medicinais ou um cartão de residência.

A conceção e montagem desta exposição resultaram de um processo colaborativo entre moradores, artistas visuais e a autarquia local, que cedeu os materiais necessários à montagem.

Salienta-se o contributo generalizado dos moradores, em particular da equipa de moradores que se organizou a fim de dar apoio à montagem, contribuindo efetivamente para a realização deste projeto expositivo e curatorial, colaborando na sua construção e implementando metodologias próprias da construção das casas do bairro.

Espera-se que este projeto possa contribuir para a discussão do processo colaborativo - habitualmente circunscrito à teoria de arte e menos discutido pelos intervenientes diretos no processo colaborativo. Como tal, procurou-se analisar e descrever a relação entre os vários intervenientes 
e as disciplinas colaborantes nas diversas fases do projeto. Incluindo o contributo dos moradores, dos antropólogos e o papel dos artistas na mediação deste processo, definido por diferentes zonas de contacto, negociação e criação.

O envolvimento com os moradores e o bairro foi uma condição essencial para a realização do projeto, na medida em que se procurou criar uma imagem do bairro informada pelos próprios moradores, que constituísse um contraponto às imagens veiculadas pela opinião pública, associadas ao crime, à violência e à pobreza, contribuindo gradualmente para o distanciamento e isolamento destas comunidades.

Nesta aproximação procurou-se sempre interrogar e envolver os moradores, para que as imagens que daqui emergissem pudessem contribuir para salvaguardar a identidade local.

A possibilidade de se intervir sobre estes materiais e a autonomia artística deram lugar a ficções e a memórias deste lugar, contribuindo assim para a definição de uma imagem estética negociada.

Com a continuidade e o alargamento desta discussão visa-se igualmente contribuir para a incorporação destes lugares e comunidades.

\section{Referências bibliográficas}

Bishop, Claire (2006), "The Social Turn: Collaboration and its Discontents", Artforum, 44(6), 178-183.

Borges, Sofia (2010) "Quando os outros colaboram na prática artística. Estudo sobre o processo colaborativo e a criação artística”. Dissertação de Mestrado em Estudos Curatoriais. Faculdade de Belas Artes de Lisboa - Universidade Técnica de Lisboa e Fundação Calouste Gulbenkian. Lisboa.

Favaretto, Celso F. (2010), "Deslocamentos: entre a arte e a vida", in Rodrigo Duarte e Romero Freitas (orgs.), Congresso Internacional: Deslocamentos na Arte. Belo Horizonte: Programa de Pós-Graduação em Filosofia da UFOP, Programa de Pós-Graduação em Filosofia da UFMG, Associação Brasileira de Estética - ABRE, 65-77. Consultado a 05.05. 2011, em http://www.abrestetica.org.br/deslocamentos/deslocamentos.pdf.

Foster, Hal (2005), "O artista como etnógrafo", in Manuela Ribeiro Sanches (org.), Deslocalizar a Europa. Antropologia, arte, literatura e história na pós-colonialidade. Lisboa: Cotovia, 259-296.

Kester, Grant (2004a), "Conversation Pieces: The Role of Dialogue in Socially-Engaged Art”, University of San Diego, California. Consultado a 30.03.2012, em http://www.grantkester.net/resources/Conversation+Pieces_ +The+Role+of+Dialogue+in+Socially-Engaged+Art.pdf. 
Kester, Grant (2004b), Conversation Pieces: Community and Communication in Modern Art. California: University of California Press.

Kester, Grant (2010), “Collaborative Practices in Environmental Art”, Greenmuseum. org. Consultado a 24.03.2011, em http://www.greenmuseum.org.

Pereiro, Xerardo (2004-2005), "Tema 5: Metodologia da Investigação antropológica Apontamentos de Antropologia Cultural”, Universidade de Trás-os-Montes e Alto Douro - UTAD. Consultado a 30.03.2012, em http://www.trabalhosfeitos.com/ ensaios/Tema-5-Antropologia-Cultural-2006-2007-Doc/277029.html. 
